


\section{A fotografia de casamento como fonte, documento e chave de leitura em uma investigação}

Wedding photography as a source, document and a key feature in an investigation

Resenha de: SCHNEID, Frantieska Huszar. Vestidos da memória: os registros de casamento em um álbum de família. Curitiba: Editora Prismas, 2018. 
CAROLINE MÜLLER ${ }^{1}$

ORCID: https://orcid.org/0000-0002-7486-0359

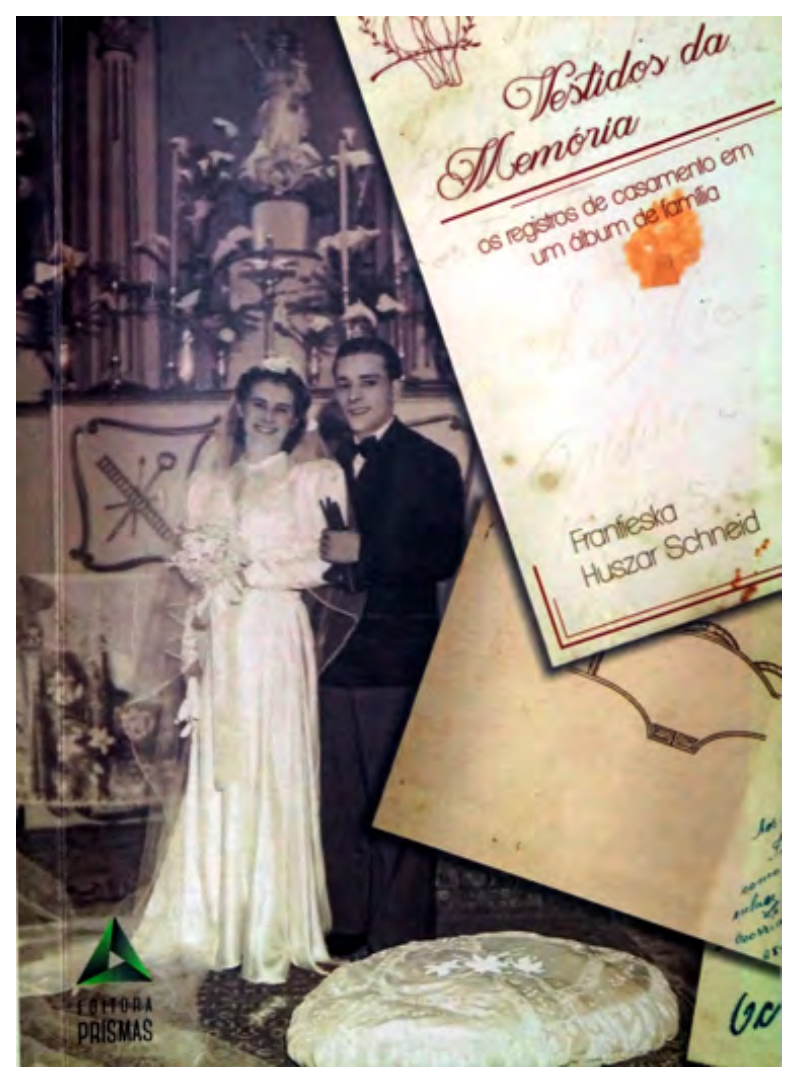

São muitos os artefatos que habitam e permanecem em repouso nos nossos armários, cristaleiras e cômodas, com a possibilidade de um dia serem revisitados, reconfigurados ou até mesmo descartados. Nesse livro, um álbum de família é retirado da gaveta e consultado para, então, ser interpretado como fonte documental. A generosidade da autora quanto ao estilo de escrita adotado contribui para que pesquisadores(as), profissionais da área da moda e simpatizantes do tema possam acessar com facilidade esta produção publicada em 2018, decorrente de sua dissertação defendida em 2015 no Programa de Pós-Graduação em Memória Social e Patrimônio Cultural da Universidade Federal de Pelotas (UFPel).

A questão central que moveu Frantieska Huszar Schneid foi compreender de que modo as fotografias contidas no álbum, em especial as de casamento e os vestidos de noiva ali representados, podem se tornar suportes de memória e dispositivos capazes de consagrar uma ideia de família. Seu objetivo esteve pautado em reconstruir narrativas sobre o rito de passagem do casamento por meio de fotografias localizadas em um álbum de família. 0

\footnotetext{
${ }^{1}$ Mestre em Design. Doutoranda em Design pela Universidade Federal do Paraná. E-mail: carolinemuller. design@gmail.com. Lattes: http://lattes.cnpq.br/3636756727375869.
} 
período histórico deste estudo compreende os anos entre 1940 e 1969, intervalo de tempo em que, segundo a autora, era habitual o compartilhamento de imagens entre pessoas.

O álbum, reconhecido não somente como um meio para o arquivamento de fotografias, é também um recorte da narrativa familiar. São momentos do passado que foram escolhidos para serem lembrados e acessados em diversas temporalidades. Logo, o argumento é de que as imagens fotográficas guardadas seriam, então, recordações familiares, um tipo de materialidade que atua no processo de constituição desses grupos. Rememorar os eventos, as roupas utilizadas, as pessoas que fizeram parte daquele instante registrado são fatores que ajudam a construir a identidade da família.

Assim como as roupas, os álbuns de fotografias têm cheiro, cor, textura e marcas promovidos pelo uso ou pelo tempo. São materialidades que foram produzidas e perpetuadas a partir do trabalho e da escolha humana. Mantê-los escondidos da poeira e das outras possíveis intempéries, seja com papel de seda, envelopes ou por meio de encadernações são tentativas de eternizar um tempo, uma paixão e/ou um afeto. Isso lembrou-me uma passagem de Adélia Prado, que em 1976 nos presenteou com um poema chamado "0 vestido", tendo com ele a possibilidade de ponderarmos que as materialidades nos guardam, nos habitam e nos constituem como pessoas.

No armário do meu quarto escondo de tempo e traça meu vestido estampado em fundo preto.

É de seda macia desenhada em campânulas vermelhas à ponta de longas hastes delicadas.

Eu o quis com paixão e o vesti como um rito, meu vestido de amante.

Ficou meu cheiro nele, meu sonho, meu corpo ido.

É só tocá-lo, volatiza-se a memória guardada:

eu estou no cinema e deixo que segurem minha mão.

De tempo e traça meu vestido me guarda (PRADO, 2008).

Em certa medida, o álbum de fotografias de casamento da família de Frantieska Schneid tem habitado sua trajetória de vida. Professora, pesquisadora e entusiasta da moda desde a sua infância, Schneid também é filha de estilista e neta de costureira. Isso a leva a aproximar-se dos álbuns de família de sua avó, Thereza da Silva Schneid, e de consequentemente construí-los como fonte de pesquisa. No total foram registradas 230 fotografias, e destas 13 foram selecionadas para análise. As imagens são lembranças de amigos, familiares e conhecidos de Thereza, bem como da mãe e da avó de Thereza, o que nos permite pensar que as práticas de colecionamento de fotografias eram recorrentes entre as mulheres. A multiplicidade de imagens reunidas por elas tornou-se uma espécie de sistematização de memórias, evidenciando, assim, temporalidades familiares, afetos, desejos, valores e ideais de vida.

A possibilidade de tratar uma imagem fotográfica como documento está alinhada à abordagem da Nova História, tradição francesa que contribuiu, especialmente a partir dos 
anos de 1970, com a maneira de se pensar os estudos históricos. Peter Burke (2011) assinala que houve uma ampliação de temas, abordagens e fontes para registro e documentação. A chamada "história vista de baixo", por exemplo, passa a considerar as vozes de pessoas comuns, convidando-as para a construção de narrativas sobre o seu próprio passado. Relatos orais, imagens, diários e jornais passam a ser utilizadas de forma legítima.

Por considerar importante compreender os sentidos e as histórias vinculadas à família da guardiã, a autora traz para a análise os olhares, as lembranças e as versões de Thereza sobre aqueles momentos capturados. Para transformar os relatos orais em fonte, são acessados e incorporados os princípios da História Oral - uma postura metodológica que interpreta e escreve histórias por intermédio da escuta das pessoas.

No tocante ao percurso da escrita, o texto está dividido em 4 capítulos. Por ser um livro que é fruto de uma dissertação, a organização do documento é semelhante à de uma produção acadêmica. 0 primeiro momento é dedicado à introdução, com a intenção de situar o(a) leitor (a), apresentando o problema de pesquisa, objetivos, método, delimitações, referencial teórico e a divisão do texto.

No capítulo 1, denominado "Fotografia como suporte de memória", encontramos discussões acerca das teorias sobre fotografia enquanto fonte e plataforma de análise. Há constantemente um esforço em perceber de que modo elas podem colaborar nos processos de rememoração e na construção de narrativas familiares. São pistas, marcas, rastros, indícios e evidências que estão em constante diálogo com quem as observa. 0 álbum de família é aqui delimitado como sendo um conjunto de fotografias que permanece armazenado, exposto e/ou organizado, com a intenção de que represente a memória coletiva do grupo.

Outro ponto destacado é no que se refere às lembranças e esquecimentos que a produção da imagem traz. 0 que foi retratado e por quais motivos? E as outras possibilidades de cenas, episódios e situações que não foram escolhidas para serem materializadas em fotografias? O esforço em eternizar esses momentos é um trabalho sobre o tempo, na tentativa de reconstruir no presente algo que já aconteceu.

0 capítulo 2, intitulado "A família, a mulher, a religiosidade e o matrimônio em fotografias de casamento" é dedicado à caracterização e contextualização do modelo de família encontrado nas fotografias. Toma-se como princípio o arranjo da família estudada, que está situada na cidade de Pelotas - Rio Grande do Sul, de religião católica, classe média e formada por marido, mulher e três filhos. A autora indica que nesse tipo de arranjo há demarcações de práticas e espaços reconhecidos como femininos e masculinos. Aqui são problematizados assuntos como a educação dessas meninas e suas necessidades enquanto futuras mulheres e esposas. 0 rito do casamento, para então constituir uma família, acompanhava a trajetória de muitas mulheres, desde a preparação do enxoval, a construção dos saberes domésticos até o amor incondicional ao marido e aos filhos. Ao homem eram dadas características como o "provedor" e o "chefe" da família, aquele que tinha o poder e a tarefa de tomar decisões pela família.

Apesar dos estudos de gênero não serem pontos selecionados para discussão, penso que seria interessante salientar que nesse processo de constituição das identidades de gênero, vivemos e somos construídas a partir de espaços normativos e de forma polarizada. 
Nesse sentido, os espaços e as tarefas ocupadas por homens e mulheres estão, constantemente, em relação e disputa.

Um ponto a destacar é que, apesar da normativa indicar que a mulher deveria ocupar o espaço doméstico como "dona de casa", Thereza nos apresenta a sua versão de mulher no período: casou-se com um homem que adoeceu quando estava grávida do terceiro filho e, por esse motivo, utilizou a máquina de costura e suas ferramentas para o sustento da família. Por meio de suas narrativas podemos compreender as motivações, aprendizados e o seu carinho pela prática da costura que a levou a se constituir enquanto mulher.

É neste item também que é reforçado o reconhecimento do tipo de mulher em estudo como figura de guardiã das histórias da família, além de ser a responsável pelos ensinamentos morais, éticos e religiosos dos filhos e netos. 0 álbum de família está atravessado nesse emaranhado de ações, sendo um arquivo que mantém, nas palavras de Silva (2008), "os familiares sobreviventes" - aqueles que estiveram presentes em acontecimentos dignos de se tornarem um rito. Para Silva, “a originalidade da observação do álbum é que sua foto existe para ser falada” (SILVA, 2008, p. 38). E é isso que Schneid propõe no capítulo seguinte, que é acessar o álbum de sua família em diálogo com a avó.

Para aqueles(as) que apreciam as narrativas visuais, elas aparecem somente no capítulo 3, o que para mim é uma surpresa, visto que a própria autora menciona que não encara as imagens apenas como ilustrações, mas sim uma narrativa e uma estratégia discursiva de contar histórias. Intitulado "O tempo da memória nas camadas da imagem", considero o capítulo de maior fôlego enquanto inovação e contribuição acadêmica, pois é nele que a autora constrói um método de análise das fotografias e nos convida a olhar para as imagens em cruzamento com as fontes orais.

Sua primeira estratégia foi realizar uma "leitura fotográfica", construindo elementos que reconhece como básicos e essenciais. Itens como número da foto, data, elementos do noivo e da noiva, dedicatória e dimensão, por exemplo, contemplam essa primeira etapa. Em seguida é realizada uma descrição das imagens, analisando-se aspectos como materialidade, conservação, dedicatórias e legendas, cenário, trajes e poses. Considero que, ao propor um método original de análise, seria valioso apresentar os critérios de seleção e as referências que a levaram a selecionar estes aspectos e não outros.

Feito isso, a autora esforça-se em unir a oralidade com a visualidade, propondo um modelo de ficha que consiga contemplar as duas camadas de informação. Para tanto, a imagem é centralizada no documento e as oralidades são apresentadas por meio de frases que foram localizadas nas entrevistas. Sua intenção com isso é registrar e organizar as lembranças e aquilo que não pode ser acessado apenas pelas imagens.

0 resultado é um material descritivo a partir do qual será possível desencadear trabalhos futuros. Ao fim do livro, são indicadas algumas considerações sobre os resultados alcançados, dentre os quais chamo a atenção para a relação que a autora faz da fotografia de casamento como parte não somente do rito matrimonial, mas também da família que investiga.

Conhecer o trabalho de Schneid nos permite acessar um tema relevante para os estudos de História da Indumentária e da Moda no Brasil, especialmente por evidenciar espaços 
que ultrapassam o eixo Rio-São Paulo, oportunizando outras chaves de leitura e problematizações. Temas como as relações de gênero, processos de catalogação e pesquisa em arquivos, além de histórias sobre os modos de fazer e produzir moda na cidade em Pelotas são outros possíveis caminhos a serem desbravados.

Pensando no objetivo proposto pela pesquisadora, acredito que relacionar os sentidos inscritos e observados nas fotografias com a identidade da família em análise qualificaria positivamente o trabalho. 0 que está contido nas fotografias que caracteriza, legitima e consagra a família em estudo? 0 que nos é apresentado são pistas das relações sociais estabelecidas, os tipos de vestimenta e os espaços pelos quais a família circulava, mas discuti-los e pô-los em relação poderia contribuir para alcançar o objetivo estabelecido, que foi de "investigar o papel que fotografias de casamento exercem como suporte de memória familiar e como podem sagrar a ideia de família através do registro dos momentos celebráveis" (SCHNEID, 2018, p. 27).

Ao falar de Thereza, Frantieska Schneid também fala sobre ela mesma. Sua dupla participação neste processo, enquanto neta e investigadora, evidencia que não há neutralidade em uma pesquisa científica e tampouco precisamos nos distanciar de nossas trajetórias de vida para construir uma dissertação ou tese, porque a vida é um conjunto de nós. E os álbuns de fotografia, as roupas e tantos outros artefatos que depositamos nos armários e gavetas fazem parte desses tantos nós que fomos, somos e seremos.

\section{Referências}

BURKE, Peter. Abertura: a nova história, seu passado e seu futuro. In: BURKE, Peter (org.). A escrita da história: novas perspectivas. Tradução Magda Lopes. São Paulo: Editora Unesp, 2011.

PRADO, Adélia. Bagagem. Rio de Janeiro: Record, 2008.

SILVA, Armando. Álbum de família: a imagem de nós mesmos. Tradução Sandra Martha Dolins. São Paulo: Editora Senac São Paulo, 2008. 